\title{
Herbarium specimens can reveal impacts of climate change on plant phenology; a review of methods and applications
}

\author{
Casey A Jones ${ }^{\text {Corresp., }}{ }^{1}$, Curtis C Daehler ${ }^{1}$ \\ ${ }^{1}$ Department of Botany, University of Hawaii at Manoa, Honolulu, HI, United States \\ Corresponding Author: Casey A Jones \\ Email address: jonesc22@hawaii.edu
}

Studies in plant phenology have provided some of the best evidence for large-scale responses to recent climate change. Over the last decade, more than thirty studies have used herbarium specimens to analyze changes in flowering phenology over time, although studies from tropical environments are thus far generally lacking. In this review, we summarize the approaches and applications used to date. Reproductive plant phenology has primarily been analyzed using two summary statistics, the mean flowering day of year and first-flowering day of year, but mean flowering day has proven to be a more robust statistic. Two types of regression models have been applied to test for associations between flowering, temperature and time: flowering day regressed on year and flowering day regressed on temperature. Most studies analyzed the effect of temperature by averaging temperatures from three months prior to the date of flowering. On average, published studies have used 55 herbarium specimens per species to characterize changes in phenology over time, but in many cases fewer specimens were used. Geospatial grid data are increasingly being used for determining average temperatures at herbarium specimen collection locations, allowing testing for finer scale correspondence between phenology and climate. Multiple studies have shown that inferences from herbarium specimen data are comparable to findings from systematically collected field observations. Understanding phenological responses to climate change is a crucial step towards recognizing implications for higher trophic levels and large-scale ecosystem processes. As herbaria are increasingly being digitized worldwide, more data are becoming available for future studies. As temperatures continue to rise globally, herbarium specimens are expected to become an increasingly important resource for analyzing plant responses to climate change. 
1 Herbarium specimens can reveal impacts of climate change on plant phenology; a review of

2 methods and applications

3

4 Casey A. Jones ${ }^{1}$, Curtis C. Daehler ${ }^{1}$

5

61 Department of Botany, University of Hawaii at Manoa, Honolulu, Hawaii

7

8 Corresponding Author:

9 Casey Jones ${ }^{1}$

103190 Maile Way, Honolulu, HI 96822, U.S.A

11 Email address: jonesc22@hawaii.edu

12

13

14

15

16

17

18

19

20

21

22

23 
25

26

27

28

29

30

31

32

33

34

35

36

37

38

39

40

41

42

43

44

45

46

PeerJ reviewing PDF | (2017:11:22000:2:0:NEW 11 Mar 2018) 
47 Abstract

48 Studies in plant phenology have provided some of the best evidence for large-scale responses to

49 recent climate change. Over the last decade, more than thirty studies have used herbarium specimens to analyze changes in flowering phenology over time, although studies from tropical environments are thus far generally lacking. In this review, we summarize the approaches and applications used to date. Reproductive plant phenology has primarily been analyzed using two summary statistics, the mean flowering day of year and first-flowering day of year, but mean flowering day has proven to be a more robust statistic. Two types of regression models have been applied to test for associations between flowering, temperature and time: flowering day regressed on year and flowering day regressed on temperature. Most studies analyzed the effect of temperature by averaging temperatures from three months prior to the date of flowering. On average, published studies have used 55 herbarium specimens per species to characterize changes in phenology over time, but in many cases fewer specimens were used. Geospatial grid data are increasingly being used for determining average temperatures at herbarium specimen collection locations, allowing testing for finer scale correspondence between phenology and climate. Multiple studies have shown that inferences from herbarium specimen data are comparable to findings from systematically collected field observations. Understanding phenological responses to climate change is a crucial step towards recognizing implications for higher trophic levels and large-scale ecosystem processes. As herbaria are increasingly being digitized worldwide, more data are becoming available for future studies. As temperatures continue to rise globally, herbarium specimens are expected to become an increasingly important resource for analyzing plant responses to climate change. 
70

71 Carl Linnaeus pioneered the study of phenology when he outlined methods for investigating associations between flowering and climate in the 1700s (Linnaeus 1751; von Linné, Freer, S.,

trans, 2003; Puppi 2007). Around 1850, Charles Morren introduced the term "phenology" to describe his observational studies of yearly flowering (Morren 1853 ;Demarée \& Rutishauser 2009). Early field studies of plant phenology have been thoroughly reviewed by van Schaik et al. (1993), Fenner (1998) and Forrest et al. (2010). Long-term observations in field studies have provided a valuable resource for analyzing phenological responses to recent climate change (Walther et al. 2002; Parmesan \& Yohe 2003). A growing need for historical data that allows for the exploration of ecological implications of climate change prompted researchers to look to herbarium specimens. A few phenology studies such as Borchert et al. (1996) and Rivera \& Borchert (2001) used herbarium specimens to study flowering periodicity, but not in the context of climate change. The first study to use herbarium specimens to understand phenological responses to climate change was published in 2004 by Primack et al. (2004). Primack et al. (2004) analyzed 372 specimen records (1885-2002) and found flowering had advanced approximately eight days over the last century. Between 2004 and 2017, more than 30 studies were published using herbarium specimens to examine changes in phenology in response to climate change.

The most common approach found in studies using herbarium specimens follows the procedure set by Primack et al. (2004). This can be summarized as collecting Julian dates from herbarium specimens, collecting long-term temperature data from an independent source, and then using regression analyses to analyze correlations between Julian dates, temperatures and time (Primack et al. 2004; Miller-Rushing et al. 2006; Gallagher et al. 2009; Robbirt et al. 2011; Gaira et al. 
93 2011; Molnár et al. 2012; Panchen et al. 2012; Park 2012; Primack and Miller-rushing 2012; Li

94 et al. 2013; Calinger et al. 2013; Hart et al. 2014; Rawal et al. 2015; Park \& Schwartz 2015).

95 Primack et al. (2004) recorded the date of collection from each herbarium specimen and then

96 extracted Julian dates from the collection dates. A Julian date is a value between 1 and 365

97 corresponding to the day of year when the specimen was collected. Linear regression models are

98 also the most widely used statistical models in field studies investigating flowering phenology

99 (Zhao et al. 2013).

100 An early criticism of using herbarium specimens was that plant parts preserved as herbarium

101 specimens might not have been collected during their peak flowering season, potentially biasing

102 interpretations (Lamoureux 1972). Daru et al. (2017) also found spatial, temporal, trait,

103 phylogenetic, and collector biases among herbarium specimen samples. Daru et al. (2017)

104 concluded that while some of these biases can be accounted for using statistical approaches,

105 future herbarium collections should focus on filling large gaps in the data. Other studies have

106 found that large sample sizes afforded by herbarium specimens, and the use of mean flowering

107 times (mean of Julian dates), could yield valid inferences, even if specimens were not collected

108 at the time of peak flowering (Primack 2004; Bertin 2015). Collector bias and plant size choice

109 have also been overcome by statistical analyses when mean flowering times were used as the

110 variable of interest, rather than the date of first-flowering (Robbirt et al. 2011; Davis et al. 2015).

111 Most of the studies we reviewed used two types of linear regression models to show evidence of

112 associations between phenology and climate change (Table 1). These studies regressed

113 flowering day on temperature (82\%) and flowering day on year (64\%) (Table 1). These studies

114 have primarily been conducted with specimens from herbaria in temperate latitudes such as the

115 Eastern Himalayas (Gaira et al. 2011; Li et al. 2013; Gaira et al. 2014; Hart et al. 2014), 
116 Southern Australia (Gallagher et al., 2009; 2012; Rawal et al., 2015), Northern Europe (Robbirt

117 et al. 2011; Diskin et al. 2012; Molnár et al. 2012), and North America (Primack et al. 2004;

118 Lavoie and Lachance 2006; Miller-Rushing et al. 2006; Primack 2009; Neil et al. 2010; Panchen

119 et al. 2012; Park 2012; Primack and Miller-rushing 2012; Searcy 2012; Calinger et al. 2013; Park

120 2014; Park \& Schwartz 2015; Bertin 2015; Davis et al. 2015). Although studies by Borchert

121 (1996) and Zalamea et al. (2011) analyzed flowering periodicity in tropical plants using

122 herbarium specimens, we found no study to date that has used herbarium specimens to analyze

123 effects of recent climate change in a tropical region. In this review, we examined how studies

124 chose sample sizes, flowering specimens, temperature averages and geographical scale in their

125 analyses. We also examined how these studies validated the use of herbarium specimens and we

126 provide suggestions for methods to be used in future studies.

128 Survey Methodology

129 Between 2015 and 2017, we compiled and reviewed studies that used herbarium specimens to assess climate change and flowering phenology. We searched Web of Science (1900 - present),

131 JSTOR (1665 - present) and Google Scholar for studies containing the terms herbarium, specimen, phenology, and climate change. The methods of each study were reviewed for; sample size, determining flowering status of specimens, approach to determining temperatures, geographic variation, and any validations of the use of herbarium specimens (e.g. comparisons to is discussed; sample sizes and regression methods were also summarized (Table 1).

138 Specimen sample sizes 
139 Sample size, or the number of specimens used per species, varied across studies (Table 1). The

140 minimum number of specimens used per species was occasionally as low as two or three records

141 (Searcy 2012). Some studies using herbarium data have set a minimum number of herbarium

142 specimens per species or a minimum time range for collections in order to more accurately

143 estimate phenologies and change over time. Calinger et al. (2013) and Gallagher et al. (2009) set

144 a minimum of 10 specimens in order to meet statistical assumptions of different models. Molnár

145 et al. (2012), eliminated a species from analyses because collections only yielded dates across an

146 eight year time span. Park \& Schwartz (2015) eliminated species with records that spanned less

147 than three years. Neil et al. (2009) organized species into functional groups (spring ephemerals,

148 spring shrubs, fall ephemerals, winter-spring ephemerals, and winter-spring shrubs) in order to

149 overcome the problem of low sample sizes for each species but found that responses of

150 individual species varied greatly within functional groups.

151 Several studies found sample size had a greater influence on first-flowering estimates than on

152 mean flowering estimates. Miller-Rushing \& Primack (2008) used field data and found that

153 small sample sizes led to biased estimations of first-flowering dates, but mean flowering day was

154 not biased by sample sizes. Moussus et al. (2010) investigated sample sizes by simulating 10

155 known phenological estimators, such as mean flowering day and first-flowering date. After

156 comparing known phenological shifts from simulated sample data with shift estimations from

157 models using the same data, Moussus et al. (2010) concluded that first-flowering dates were

158 inaccurate because they showed much greater differences in comparisons than mean flowering

159 day. Low sample sizes prompted Bertin (2015) to provide a detailed analysis of how sample size

160 affected mean, median, range, early flowering and late flowering summary statistics. In random

161 simulations comparing sample sizes, mean flowering day values deviated less than five days for 
162 species with as few as four samples (Bertin 2015). Bertin (2015) concluded that the mean was a

163 more robust measure of phenology than other estimators of early flowering. Bertin (2015) also

164 showed that by increasing the sample size to 20 , mean flowering times deviated only one to two

165 days. A recent study by Pearse et al. (2017) used a Weibull distribution to estimate the start of

166 the process of flowering rather than using only first-flowering observations. Pearse et al. (2017)

167 showed that by controlling for differences in sampling, first-flowering, peak-flowering (median)

168 and cessation of flowering show similar changes over time in response to climate change. The

169 model used by Pearse et al. (2017) was also shown to be consistent with changes in mean-

170 flowering from a separate sample using an early time period.

171 Larger sample sizes may be required if phenology varies across a species' geographic range. In

172 order to analyze species distributions using herbarium specimens, van Proosdij et al. (2016)

173 found that the minimum number of herbarium specimens sampled should be between 14 and 25

174 depending on the geographical range of the species. The van Proosdij et al. (2016) study used

175 simulated species to assess the minimum herbarium samples required for acceptable model

176 performance in both virtual and real study areas. Some species with narrow geographical ranges

177 could be modeled with as few as 14 herbarium records while wide ranging species could be

178 satisfactorily modeled with a minimum of 25 records (van Proosdij et al. 2016). Based on these

179 studies, we recommend caution when interpreting results from samples sizes with fewer than 30

180 records (Miller-Rushing et al. 2008; Moussus et al. 2010; Bertin 2015). The average sample size

181 across studies in this review was about 55 records per species (Table 1.). We also recommend

182 using the mean flowering day of year rather than averages of first flowering dates (Calinger et al.

183 2013; Gallagher et al. 2009; Pearse et al. 2017). 
Determining flowering status of specimens

186 Some studies have simply recorded the presence or absence of flowers from herbarium

187 specimens as an indicator of flowering, but other studies have used more detailed criteria to

188 assess flowering status on specimens. Haggerty et al. (2012) provided a primer to assist researchers with collecting data from herbarium specimens. Haggerty et al. (2012) suggested researchers assign a phenophase for each specimen, such as pre-flowering, first-flowering or peak flowering. Haggerty et al. (2012) also noted that researchers must assume the stem on the

192 herbarium sheet represents the flowering phenophase for the entire plant. Past studies, such as Diskin et al. (2011), have used a scoring system from 1 to 5 to categorize phenophase stages raging from "no flowers" to "end of fruiting" on each specimen. Diskin et al. (2011) categorized flowering as 50\% of buds open on the specimen. Calinger et al. (2013) also categorized flowering as $50 \%$ of flower buds in anthesis to ensure that the samples were in peak flowering.

197 For a species with an inflorescence, Davis et al. (2015) only counted specimens as flowering if 198 greater than $75 \%$ of flowers were open. Standardization of phenological terms remains a core challenge of mining phenological data (Willis et al. 2017). Initiatives such as the Plant Phenology Ontology (PPO) working group are currently structuring phenological terms for more uniform application across studies (Willis et al. 2017).

Studies in temperate regions have used varying methods to determine flowering status for species with long flowering durations. For example, Molnár et al. (2012) and Bertin (2015) excluded species that flowered outside of the peak flowering season of the region, defined as the period from late-spring to early-summer. Molnár et al. (2012) removed one species because its peak flowering date was in September and focused on 40 other taxa that had flowering peaks

207 from in spring and early-summer. The excluded species was a strong outlier and it was 
208 suggested that autumn climate events may affect species differently than spring climate events 209 (Molnár et al., 2012). Park (2012) also removed outlier records when flowering records fell 210 outside the peak regional flowering season. Flowering records before Julian day 45 and after 211 Julian day 310 were removed from analyses to reduce biases caused by winter flowering species. 212 Additionally, Park (2012) removed records that were 150 days after the median flowering date

213 for each species to reduce errors caused by any second flowerings that can happen in autumn 214 months. Several other studies removed taxa with long flowering durations to reduce variance 215 among species. Bertin (2015) excluded native weedy species with flowering durations from 216 spring to fall. Gallagher et al. (2009) only used species with a flowering duration of less than 217 three months. Panchen et al. (2012) chose to use only species with clear beginning and ending 218 points to investigate long and short flowering duration. Panchen et al. (2012) found that plants 219 with shorter flowering durations required smaller sample sizes to produce significant results 220 when regressing flowering day on year.

221 Other studies such as Calinger et al. (2013) and Lavoie \& Lachance (2006) disregarded the effect 222 of flowering duration and noted the results of Primack et al. (2004), which reported no bias 223 associated with long or short flowering durations when mean estimations are analyzed. Plants in tropical regions often have long flowering durations (van Schaik 1993; Fenner 1998), but as long as flowering is not continuous throughout the year, methods applied to temperate regions should 226 also yield valuable insight into effects of climate change on phenology in the tropics. While 227 studies using herbarium specimens to analyze long-term changes have been limited to temperate regions, future studies could use circular statistics to analyze long-term phenological changes in tropical regions (Fisher 1993; Morellato et al. 2010). Circular statistics have been used to analyze flowering phenology in several tropical field studies, but these studies lacked long-term 
231 climate change analyses (Novotny \& Basset 1998; Morellato et al. 2000; Cruz et al. 2006;

232 Rogerio \& Araujo 2010; Tesfaye et al. 2011; Nadia et al. 2012; Nazareno \& dos Reis 2012;

233 Staggemeier et al. 2012; Carvalho \& SartorWe2015; Kebede \& Isotalo 2016).

Averaging temperatures

236 The foundational study by Primack et al. (2004) examined temperature averages from three

237 calendar months prior to the specimen flowering date, with the assumption that flowering date is

238 a function of temperatures experienced in past months. Field investigations such as Fitter et al.

239 (1995) have shown temperature averages from different sets of months preceding flowering

240 affected flowering phenology in different ways. More recently, Calinger et al. (2013) chose to

241 regress the month of flowering with temperature averages from each of the eleven months prior

242 to flowering. They found that temperature averages from three months prior to the date of

243 flowering showed the strongest correlations with flowering (Calinger et al. 2013). Robbirt et al.

244 (2011) investigated three sets of temperature averages over three month intervals and also found

245 that three months prior to flowering had the most predictive power. Similarly, Rawal et al.

246 (2015) regressed flowering on temperature averages for each species from 1, 3, 6, 9, and 12

247 months prior to flowering, because responses can vary by species. Rawal et al. (2015) also

248 found that mean temperatures three months prior had the greatest influence on flowering time for 249 all species.

250 Other studies have used average temperatures from spring months because spring temperatures

251 generally have the most predictive power for flowering date (Miller-Rushing \& Primack 2008;

252 Primack et al. 2009; Robbirt et al. 2011; Calinger et al. 2013; Park 2014; Park \& Schwartz

253 2015). Bertin (2015) found an interesting trend that supported the effect of spring temperatures: 
254 the earlier a species' mean flowering time occurred in the spring, the more the species' mean

255 dates had shifted toward an earlier day of year over time. Robbirt et al. (2011) also found the

256 highest correlations of flowering day with spring temperature averages across March, April and

257 May. Calinger et al. (2013) found significant changes in flowering in response to average spring

258 temperatures (February-May) but not in response to summer temperatures (June to September).

259 Gaira et al. (2011) found the highest correlations between flowering and temperatures in earlier

260 months from December-February in a Himalayan perennial. As an alternative to using mean

261 monthly temperatures, Diskin et al. (2011) investigated the averages of temperature anomalies,

262 or deviations from the overall long-term mean, for 2, 3, and 6 month periods from January to

263 June and found averages from six months prior to flowering had the strongest correlations. Park

264 (2014) used temperature averages across three month periods from early spring to late summer

265 and found a similar trend. Temperature averages were organized into early, mid, and late

266 seasonal classes within the months of February to October. Park (2014) found warming

267 temperatures had affected species in the early spring class more than other classes. Park \&

268 Schwartz (2015) also used early, mid and late seasonal classes for spring and summer and found

269 that mid-season phenology events should be modeled differently than early or late season events.

270 Hart et al. (2014) used annual temperatures and temperatures from each season (spring, summer,

271 fall, and winter) and found significant correlations for annual and fall temperature averages, but

272 with opposite effects. Hart et al. (2014) discussed that warmer fall temperatures may delay the

273 chilling requirement for Rhododendron species, resulting in a delay in flowering while warmer

274 annual temperatures will lead to advances in flowering overall. Other studies found annual

275 temperature means were as useful as spring temperatures. Davis et al. (2015) found similar

276 results between spring and annual temperature averages and used annual averages in analyses. 
277 Gallagher et al. (2009) also used annual temperature means for analyses and explained that

278 seasonal means were correlated with annual means.

279 We recommend investigating the effect of temperature by analyzing averages from multiple sets

280 of months prior to flowering for each species rather than using only one fixed spring interval or

281 only annual temperatures (Diskin et al. 2011; Robbirt et al. 2011; Calinger et al. 2013). Caution

282 should be taken when analyzing temperature averages from the same months prior to flowering

283 for all species when flowering month varies by species. For example, when analyzing the effect

284 of temperature averages from three months prior for all species, Calinger et al. (2013) found that

285 for many species, flowering was correlated with temperatures three months earlier, yet for

286 species with an earlier mean flowering day in April, January temperatures (three months prior to

287 flowering) did not predict flowering date; instead, temperature averages from the months of

288 February, March and April were better predictors for those species.

290 Geographic variation

291 Among species that have broad geographic ranges, differences in climate in different parts of the

292 species' range can complicate attempts to correlate a species' flowering day with temperature.

293 Several methods have been used to account for climate variability across a species' range. An

294 early study by Lavoie \& Lachance (2006) investigated the effects of climate variation on the

295 phenology of Coltsfoot (Tussilago farfara L.) across a range of about 10,000 km2 in Quebec,

296 Canada. Temperature data from 88 meteorological stations were averaged together across this

297 range. To account for early snow cover melt in the southern part of this range, flowering dates

298 from individuals in southern locations were normalized with individuals in northern locations by

299 subtracting extra periods of snow cover from individuals in the north. The adjusted dates 
300 indicated flowering occurred 33 days earlier over the last century while original (unadjusted)

301 dates indicated flowering occurred 19 days earlier over the last century.

302 While the study by Lavoie \& Lachance (2006) adjusted actual dates for analyses, more recent

303 studies mostly account for climate variation using georeferenced climate data at various scales.

304 Calinger et al. (2013) accounted for climate variation across Ohio by using temperature averages

305 from ten US Climate Divisions across the state, each about 8,000 km2. A total of 344 Climatic

306 Divisions were established across the contiguous United States in 1895 in order to monitor

307 climate records more accurately. These divisions have now accumulated about 100 years of

308 climate records (Guttman \& Quayle 1996). A later study by Park (2014) used average

309 temperatures across the U.S. county where each specimen was collected.

310 Other studies accounted for climate variation across longitude, latitude, or elevation. Robbirt et

311 al. (2011) analyzed the geographical effect of longitude and found that flowering occurred 4.86

312 days earlier per degree of longitude in a westward direction across the southern coastal counties

313 of England (Robbirt et al. 2011). A later study by Bertin (2015) used Hopkins' bioclimatic law

314 to normalize dates on specimens. Hopkins' (1918) generally stated that for every increase in a

315 degree of latitude, or increase of $121.92 \mathrm{~m}$ elevation, the life history events of plants and animals

316 were delayed by four days. Bertin (2015) found consistencies with Hopkins' bioclimatic law

317 using latitude and elevation and chose to normalize flowering dates by adding expected

318 phenological deviations from both latitude and elevation. Gaira et al. (2011) also analyzed

319 climate variation using elevation when temperature data were not available, assuming a $6.5^{\circ} \mathrm{C}$

320 change in temperature per 1000 m change in elevation in the Himalayan region.

321 Other studies used temperature averages across large regions. Li et al. (2013) used temperature

322 data that was averaged from 36 meteorological stations across the Tibet Autonomous Region. 
323 Molnár et al. (2012) used temperature averages from 10 meteorological stations across Hungary

324 and stated that the data were statistically indistinguishable across stations $\left(\sim 93,030 \mathrm{~km}^{2}\right)$. Park \&

325 Schwartz (2015) averaged temperatures from 13 stations across South Carolina, USA ( 82, 931

$326 \mathrm{~km}^{2}$ ). A later study by Robbirt et al. (2014) used temperature averages from an area between

327 Bristol, Preston, and London, across the United Kingdom ( 17, $\left.000 \mathrm{~km}^{2}\right)$. Robbirt et al. (2014)

328 used geographical divisions called Watsonian vice-counties specifically delineated for the

329 purposes of collecting scientific data, much like the US Climate Divisions. Robbirt et al. (2014)

330 found temperature averages were sufficient because climate variation across the Watsonian vice-

331 counties used in their study did not significantly differ.

332 In order to more accurately estimate temperature averages across a region, recent studies have

333 used Geographical Information Systems (GIS) to project finer-scale climate layers across a

334 region and extract temperature data from specific Global Positioning System (GPS) points.

335 Gallagher et al. (2009) referenced GPS locations for each specimen and extracted the

336 temperature averages at specimen GPS points from a gridded map of temperature averages

337 across Australia ( $\sim 5 \mathrm{~km} 2$ resolution). Hereford et al. (2017) also extracted climate data from 176

338 collection locations in order to analyze species distributions and phenology. Rawal et al. (2015)

339 used the nearest data point from gridded climate averages across Victoria, Australia. Edward \&

340 Still (2008) analyzed the climate envelopes of grasses by assigning GPS points to herbarium

341 specimen locations in order to extract temperature averages from gridded climate maps $\left(250 \mathrm{~m}^{2}\right.$

342 resolution). Kosanic et al. (2018) manually geo-referenced locations using herbarium specimen

343 localities and provided a methodology for assigning GPS coordinates when analyzing species

344 distributions and phenology. Standardizing methods for geo-referencing localities of herbarium

345 records without GPS coordinates could allow for more specimen data and larger sample sizes. 
346 Bloom et al. (2017) developed a comprehensive protocol for standardizing spatial accuracy of

347 geo-referenced specimen localities for species distributions.

348 Future studies of phenology could benefit from such geo-referencing methods because several

349 phenology studies only included data from specimens with GPS coordinates. Studies using GPS

350 data are able to account for climate variation with higher resolution, although accuracy still

351 depends on the underlying empirical data and modeling approach used to generate GIS climate

352 layers.

353 We recommend using the most spatially precise temperature data available, such as climate

354 divisions (Calinger et al. 2013; Robbirt et al. 2015) rather than state or region averages (Li et al.

355 2013; Park \& Schwartz 2015). Using GPS specimen data to identify local climate conditions

356 from GIS climate layers (Gallagher et al. 2009; Edward \& Still 2008) is also now generally more

357 precise and convenient in comparison to making generic and coarse-scale corrections for

358 latitude, longitude or elevation (Gaira et al. 2011; Robbirt et al. 2011; Bertin 2015). If

359 temperature averages from larger areas are used, we recommend testing for climate variability

360 across smaller divisions before using averages across the larger area (Lavoie \& Lachance 2006;

361 Molnár et al. 2012; Robbirt et al. 2015).

362

363 Validation: herbarium specimens versus field observations

364 Field data are often combined with herbarium specimen data in analyses, allowing for

365 comparison and sometimes allowing for validation of conclusions based on herbarium data

366 (Primack et al., 2004; Miller-Rushing et al. 2006; Bertin 2015). Primack et al. (2004) used

367 herbarium specimens for historic data and field observations for current data and combined the

368 two in analyses (Primack et al., 2004). Studies by Miller-Rushing et al. (2006) and Bertin (2015) 
369 also compared herbarium specimen data with field observations. Miller-Rushing et al. (2006)

370 found that phenology inferences from herbarium specimens alone differed from the combined

371 data by only about one day.

372 An early study by Borchert, (1996) found that herbarium specimen data produced slightly longer

373 flowering durations than field data, but noted that durations were mostly similar overall.

374 Borchert, (1996) and Rivera \& Borchert (2001) found phenology data from field sites largely

375 overlapped that of herbarium specimens with only slight differences. The negligible differences

376 between herbarium specimen data and field data in these studies helped justify the use of

377 herbarium specimen data to analyze phenology in more recent studies. Nevertheless, several

378 more recent studies specifically compared phenology estimates from field data to those made

379 from herbarium specimens.

380 Bolmgren \& Lonnberg (2005) compared herbarium specimen data directly to field data and

381 found the two data sets were overall highly correlated with only minor differences. For example, 382 herbarium specimens showed a slightly earlier mean flowering for spring-flowering plants than

383 field data, but the difference was not significant (Bolmgren \& Lonnberg, 2005). Later studies by

384 Robbirt et al. (2011) and Davis et al. (2015) also primarily focused on testing the validity of

385 using herbarium specimen data. Robbirt et al. (2011) used a principal axis regression analysis to

386 compare herbarium derived peak-flowering dates with field derived peak-flowering dates and

387 found a high degree of correlation. Robbirt et al. (2011) discussed how the high degree of

388 correlation between herbarium and field data also supports the notion that geographically

389 different records will not significantly alter the robustness of either data set. A study by Davis et

390 al. (2015) used a paired t-test to compare mean first-flowering day between herbarium specimens 
391 and field data and found no statistical difference. Davis et al. (2015) concluded that both

392 specimen and field data could be combined and used as a whole.

393 In order to increase sample sizes, Molnár et al. (2012) added about 2000 field observations to 394 about 5000 herbarium records, resulting in 70\% herbarium records for the study. Similarly, 395 Panchen (2012) added about 2000 field records to about 1500 herbarium records, for a total of $39643 \%$ herbarium records for the study. Searcy (2012) combined herbarium specimen and field 397 data and then split the combined data into two time periods (1863-1935 and 1994-2008).

398 Herbarium specimen data may provide some advantages over field data. Bolmgren \& Lonnberg 399 (2005) and Primack et al. (2004) noted that using herbarium specimens conserves time and 400 resources, especially when species are located in difficult to access geographical areas such as 401 mountain peaks or islands. Herbarium specimens are also collected over a greater period of time 402 from a larger geographical area while field data are often from specific localities over a shorter 403 time period (Primack et al. 2004; Bolmgren \& Lonnberg 2005; Bertin 2015; Davis et al. 2015). 404 Herbarium specimens also provide long-term records that are widely accessible for multiple 405 studies. Despite criticisms, herbarium specimen data have been shown to produce similar 406 enough results to field data that herbarium specimen data are now widely accepted in 407 phenological studies.

408

409 Conclusions

410 The use of herbarium specimens for the investigation of flowering phenology has grown 411 considerably during the past decade. As efforts to produce digital copies of specimens and label 412 information have amassed large datasets, new approaches for analyzing responses to climate 413 change are rapidly becoming available. Although small sample sizes have often been used in 
414 early studies of phenology, various factors, such as wide geographic range, may require larger 415 sample sizes. Based on recent validations, estimations of mean-flowering should be used rather

416 than first-flowering because estimates of first-flowering are more sensitive to sampling.

417 Statistically modeling the start of the flowering process appears to be another promising

418 approach to investigating how climate change has affected the beginning of a flowering cycle

419 (Pearse et al. 2017). The use of GPS data appears to be the way forward for the advancement of 420 methods in the study of phenology. GPS point data allow for correspondence with higher

421 resolution temperature data in climatically diverse geographical regions. Studies using

422 herbarium specimen data will continue to help us understand the impact of recent climate change

423 on plant reproductive phenology. Other aspects of plant phenology that can be analyzed using

424 herbarium specimens, such as fruit ripening and spring leaf emergence, have important

425 implications for higher trophic levels, which may include rare animals dependent on plant

426 resources (Everill et al. 2014; Zohner \& Renner 2014; Mendoza et al. 2017). Studies using

427 herbarium specimens have become an asset for long-term climate change vulnerability

428 assessment. These studies have begun to analyze the effects of climate change on community 429 composition (Miller-Rushing \& Primack 2008, Park 2014), species distribution (Hereford et al. 2017; Kosanic et al. 2018), coevolved plant pollinator relationships (Molnár et al. 2012; Robbirt et al. 2014), functional groups (Miller-Rushing \& Primack 2008; Panchen et al 2012; Calinger et al. 2013; Munson and Long 2017), and phylogenetic relationships (Bolmgren \& Lonnberg 2005; Molnár et al. 2012; Primack and Miller-rushing 2012). Future studies investigating phylogenetic 434 signals and plasticity are needed to further improve our understanding of adaptation and resilience to climate change. As temperatures continue to rise globally, herbarium specimens

436 will continue to be crucial resources for analyzing phenological responses to climate change. 
438 References

439 Bertin, R.I. 2015. Climate change and flowering phenology in Worcester County, Massachusetts.

440 International Journal of Plant Sciences 176: 107-119.

441

442 Bloom, T.D.S., A. Flower, E.G. DeChaine. 2018. Why georeferencing matters: Introducing a 443 practical protocol to prepare species occurrence records for spatial analysis. Ecology and 444 Evolution 8:765-777.

445

446

447

Bolmgren, K., and K. Lonnberg. 2005. Herbarium data reveal an association between fleshy fruit type and earlier flowering time. International Journal of Plant Sciences 166: 663-670.

448

449

Borchert, R. 1996. Phenology and flowering periodicity of neotropical dry forest species:

450

evidence from herbarium collections. Journal of Tropical Ecology 12: 65-80.

451

452 Calinger, K.M., S. Queenborough, and P.S. Curtis. 2013. Herbarium specimens reveal the 453 footprint of climate change on flowering trends across North-Central North America. Ecology

454 Letters 16: 1037-1044.

455

456 Daru, B.H., M. van der Bank, and T. J. Davies. 2017. Unravelling the evolutionary origins of 457 biogeographic assemblages. Diversity and Distributions 66: 1014-1016 
459 Davis, C.C., C.G. Willis, B. Connolly, C. Kelly, and A.M. Ellison. 2015. Herbarium records are

460 reliable sources of phenological change driven by climate and provide novel insights into

461 species' phenological cueing mechanisms. American Journal of Botany 102: 1599-1609.

462

463 Demarée, G.R., and Rutishauser, T., 2009. Origins of the word "phenology". Eos Transactions

464 American Geophysical Union 90, 291

465

466 Diskin, E., H. Proctor, M. Jebb, T. Sparks, and A. Donnelly. 2012. The phenology of Rubus

467 fruticosus in Ireland: herbarium specimens provide evidence for the response of phenophases to

468 temperature, with implications for climate warming. International Journal of Biometeorology 56:

$469 \quad 1103-1111$.

470

471 Edwards, E.J., and C.J. Still. 2008. Climate, phylogeny and the ecological distribution of C4

472 grasses. Ecology Letters 11:266-76.

473

474 Everill, P.H., R.B. Primack, E.R. Ellwood, E.K. Melaas. 2014. Determining past leaf-out times

475 of New England's deciduous forests from herbarium specimens, American Journal of Botany.

$476 \quad 101: 1293-1300$

477

478 Fenner, M. 1998. The phenology of growth and reproduction in plants. Perspectives in Plant

479 Ecology, Evolution and Systematics 1: 78-91.

480 
481 Fitter, A. H., Fitter, R. S. R. , Harris, I. T. B., Williamson, M.H. 1995. Relationships between 482 first-flowering date and temperature in the flora of a locality in central England. Functional 483 Ecology 9: 55-60.

484

485 Fisher, N. I. 1993. Statistical analysis of circular data. Cambridge University Press, Cambridge 486

487 Forrest, J., and A.J. Miller-rushing. 2010. Toward a synthetic understanding of the role of 488 phenology in ecology and evolution. Philosophical Transactions of the Royal Society B 365: $489 \quad 3101-3112$.

490

491 Gaira, K.S., R.S. Rawal, B. Rawat, and D. Bhatt. 2014. Impact of climate change on the 492 flowering of Rhododendron arboreum in central Himalaya, India. Current Science 106: 17354931738.

494

495

Gaira, K.S., U. Dhar, and O.K. Belwal. 2011. Potential of herbarium records to sequence 496 phenological pattern: a case study of Aconitum heterophyllum in the Himalaya. Biodiversity and 497 Conservation 20: 2201-2210.

498

499 Gallagher, R. V., L. Hughes, and M.R. Leishman. 2009. Phenological trends among Australian 500 alpine species: using herbarium records to identify climate-change indicators. Australian Journal 501 of Botany 57: 1-9.

502 
503 Guttman, N. B., and R.G. Quayle, 1995. A historical perspective of U.S. Climate Divisions.

504 Bulletin of the American Meteorological Society 77: 293-303.

505

506 Haggerty B.P, A.A. Hove, and S. J. Mazer 2012. Primer on herbarium-based phenological

507 research. Guide for college and public audiences for understanding the use of preserved plants in

508 climate change research. California Phenology Project.

509

510 Hart, R., J. Salick, S. Ranjitkar, and J. Xu. 2014. Herbarium specimens show contrasting

511 phenological responses to Himalayan climate. Proceedings of the National Academy of Sciences

512 of the United States of America 111: 10615-9.

513

514 Hereford, J., J. Schmitt, and D.D. Ackerly. 2017. The seasonal climate niche predicts phenology 515 and distribution of an ephemeral annual plant, Mollugo verticillata. Journal of Ecology 105, $516 \quad 1323-1334$.

517

518 Hopkins, A.D. 1918. Periodical events and natural law as guides to agricultural research and 519 practice. U. S. Department Of Agriculture Weather Bureau, Monthly Weather Review 643: 552042.

521

522 Kosanic, A., K. Anderson, S. Harrison, T. Turkington, and J. Bennie. 2018. Changes in the 523 geographical distribution of plant species and climatic variables on the West Cornwall peninsula 524 (South West UK). PLoS one. 13: e0191021. https://doi.org/10.1371/journal.pone.0191021 
526 Lamoureux, C.H. 1973. Phenology and reproduction of Hawaiian plants, a preliminary report.

527 Island Ecosystems, US International Biological Program, Technical Report No 24.

528

529 Lavoie, C., and D. Lachance. 2006. A new herbarium-based method for reconstructing the

530 phenology of plant species across large areas. American Journal of Botany 93: 512-516.

531

532 Li, Z., N. Wu, X. Gao, Y. Wu, and K.P. Oli. 2013. Species-level phenological responses to

533 "global warming" as evidenced by herbarium collections in the Tibetan Autonomous Region.

534 Biodiversity and Conservation 22: 141-152.

535

536 Linnaeus C. 1751, Philosophia botanica, Stockholm

537

538 Mendoza, I., C.A. Peres, and L.P.C. Morellato. 2016. Continental-scale patterns and climatic

539 drivers of fruiting phenology: a quantitative neotropical review. Global and Planetary Change.

540 148: $227-241$

541

542 Miller-Rushing, A.J., and R.B. Primack. 2008. Global warming and flowering times in Thoreau's

543 Concord: a community perspective. Ecology 89: 332-341.

544

545 Miller-Rushing, A.J., R.B. Primack, D. Primack, and S. Mukunda. 2006. Photographs and

546 herbarium specimens as tools to document phenological changes in response to global warming.

547 American Journal of Botany 93: 1667-1674. 
549 Molnár V, A., J. Tökölyi, Z. Végvári, G. Sramkó, J. Sulyok, and Z. Barta. 2012. Pollination

550 mode predicts phenological response to climate change in terrestrial orchids: a case study from

551 Central Europe. Journal of Ecology 100: 1141-1152.

552

553 Morellato, L. P. C. Alberti, L. F., and Hudson, I. L. 2010. Applications of circular statistics in

554 plant phenology; a case studies approach. In Phenological Research; Methods for Environmental 555 and Climate Change Analysis (ed. I. L. Hudson and M. R. Keatley), pp. 339-59.

556

557

Morren C. 1853. Souvenirs phénologiques de l'hiver 1852-1853. Bull de l'Académie royale des.

558 Sciences, des Lettres et des Beaux-Artes de Belgique 20:160-186.

559

560 Moussus, J., R. Julliard, and F. Jiguet. 2010. Featuring 10 phenological estimators using 561 simulated data. Methods in Ecology and Evolution 1: 140-150.

562

563 Munson, S.M., and A.L. Long. 2017. Climate drives shifts in grass reproductive phenology

564 across the western USA. New Phytologist 213: 1945-1955.

565

566 Neil, K.L., L. Landrum, and J. Wu. 2010. Effects of urbanization on flowering phenology in the 567 metropolitan phoenix region of USA: findings from herbarium records. Journal of Arid 568 Environments 74: 440-444 
570 Panchen, Z.A., R.B. Primack, T. Aniśko, and R.E. Lyons. 2012. Herbarium specimens,

571 photographs, and field observations show Philadelphia area plants are responding to climate

572 change. American Journal of Botany 99: 751-756.

573

574 Papadopulos, A.S.T., and W.J. Baker. 2011. Speciation with gene flow on Lord Howe Island.

575 Proceeding of the National Academy of Sciences 108: 1-6.

576

577 Park, I.W. 2012. Digital herbarium archives as a spatially extensive, taxonomically discriminate

578 phenological record; a comparison to MODIS satellite imagery. International Journal of

579 Biometeorology 56: 1179-1182.

580

581 Park, I.W. 2014. Impacts of differing community composition on flowering phenology

582 throughout warm temperate, cool temperate and xeric environments. Global Ecology and

583 Biogeography 23: 789-801.

584

585 Park, I.W., and M.D. Schwartz. 2015. Long-term herbarium records reveal temperature-

586 dependent changes in flowering phenology in the Southeastern USA. International Journal of

587 Biometeorology 347-355.

588

589 Parmesan, C., C. Parmesan, G. Yohe, and G. Yohe. 2003. A globally coherent fingerprint of

590 climate change impacts across natural systems. Nature 421: 37-42.

591 
592 Pearse, W.D., C.C. Davis, D.W. Inouye, R.B. Primack \& T. J. Davies. 2017. A statistical 593 estimator for determining the limits of contemporary and historic phenology. Nature Ecology \& 594 Evolution 1, 1876-1882

595

596 Primack, D., C. Imbres, R.B. Primack, A.J. Miller-Rushing, and P. Del Tredici. 2004. Herbarium 597 specimens demonstrate earlier flowering times in response to warming in Boston. American 598 Journal of Botany 91: 1260-1264.

599

600 Primack, R.B., and A.J. Miller-Rushing. 2009. The role of botanical gardens in climate change 601 research. New Phytologist 182: 303-313.

602

603 Primack, R.B., and A.J. Miller-rushing. 2012. Uncovering, collecting, and analyzing records to 604 investigate the ecological impacts of climate change: a template from Thoreau's Concord. 605 BioScience 62: 170-181.

606

607 Puppi, G. 2007. Origin and Development of Phenology as a Science. Italian Journal of 608 Agrometeorology 12: 24-29.

609

610 Rawal, D.S., S. Kasel, M.R. Keatley, and C.R. Nitschke. 2015. Herbarium records identify 611 sensitivity of flowering phenology of eucalypts to climate: implications for species response to 612 climate change. Austral Ecology 40: 117-125. 
614 Rivera, G., and R. Borchert. 2001. Induction of flowering in tropical trees by a 30-min reduction 615 in photoperiod: evidence from field observations and herbarium specimens. Tree Physiology 21: $616 \quad 201-212$.

617

618 Robbirt, K.M., A.J. Davy, M.J. Hutchings, and D.L. Roberts. 2011. Validation of biological 619 collections as a source of phenological data for use in climate change studies: a case study with 620 the orchid Ophrys sphegodes. Journal of Ecology 99: 235-241.

621

622 Robbirt, K.M., D.L. Roberts, M.J. Hutchings, A.J. Davy, R.B. Gardens, and S. Tw. 2014. Report 623 potential disruption of pollination in a sexually deceptive orchid by climatic change. Current 624 Biology 24: 2845-2849.

625

626 Searcy, K.B. 2012. Changes in the flora of the Mount Holyoke Range, Hampshire Co., 627 Massachusetts over the past 150 years (1860-2010). Rhodora 114: 113-132.

628 van Proosdij, A.S.J., M.S.M. Sosef, J.J. Wieringa, and N. Raes. 2016. Minimum required number 629 of specimen records to develop accurate species distribution models. Ecography 39: 542-552.

630

631

van Schaik, C.P., J.W. Terborgh, and S.J. Wright. 1993. The phenology of tropical forests 632 adaptive significance and consequences for primary consumers. Annual Review of Ecology and 633 Systematics 24: 353-377.

634

635 von Linné, C. 2003. Linnäus’ Philosophica Botanica. New York: Oxford University Press 636 (Translation by S. Freer). 
637

638 Walther, G.R., E. Post, P. Convey, A. Menzel, C. Parmesan, T.J.C. Beebee, and J.M. Fromentin. 639 2002. Ecological responses to recent climate change. Nature 416: 389-395.

640

641 Willis, C.G., E.R. Ellwood, R.B. Primack, C.C. Davis, K.D. Pearson, A.S. Gallinato, J.M. Yost, 642 G . Nelson, S.J. Mazer, N.L. Rossington, T.H. Sparks, and P.S. Soltis. 2017. Old plants, new 643 tricks: phenological research using herbarium specimens. Trends in Ecology \& Evolution 32: $644 \quad 531-546$.

645

Zalamea, A.P., F. Munoz, P.R. Stevenson, C.E.T. Paine, C. Sarmiento, D. Sabatier, and P.

647 Heuret. 2016. Continental-scale patterns of Cecropia reproductive phenology: evidence from 648 herbarium specimens. Proceedings of the Royal Society 278: 2437-2445.

649

650 Zhao, M.F., C.H. Peng, W.H. Xiang, X.W. Deng, D.L. Tian, X.L. Zhou, and G.R. Yu. 2013.

651 Plant phenological modeling and its application in global climate change research: overview and 652 future challenges. Environmental Reviews 21: 1-14.

653

654 Zohner, C.M. and S.S. Renner. 2014. Common garden comparison of the leaf-out phenology of 655 woody species from different native climates, combined with herbarium records, forecasts long656 term change. Ecology Letters. 17, 1016-1025 (2014) 


\section{Table $\mathbf{1}$ (on next page)}

\section{Methods of studies}

The column "Flw Day Temp" represents studies that conducted a type of regression analysis with flowering day (Flw Day) as the dependent variable and temperature average (temp) or year as the independent variable. The " $\Delta \overline{\mathrm{X}}$ " symbol represents studies that analyzed a difference in the mean flowering day between historic and current time period groups rather than using a type of regression analysis 


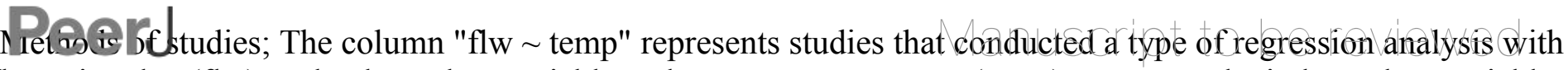
flowering day (flw) as the dependent variable and temperature average (temp) or year as the independent variables. The " $\Delta \overline{\mathrm{x}}$ " symbol represents studies that analyzed a difference in the mean flowering day between historic and current time period groups rather than using a type of regression analysis.

\begin{tabular}{|c|c|c|c|c|c|c|c|}
\hline species & specimens & $\begin{array}{c}\text { specimen } \\
\text { per species }\end{array}$ & authors & year & geographic region & $($ flw $\sim$ temp $)$ & (flw $\sim$ year $)$ \\
\hline 1 & 117 & 117 & Gaira et al. & 2011 & Eastern Himalayas & & $\mathrm{x}$ \\
\hline 1 & N/A & $\mathrm{N} / \mathrm{A}$ & Gaira et al. & 2014 & Eastern Himalayas & $\mathrm{x}$ & $\mathrm{x}$ \\
\hline 1 & 192 & 192 & Robbirt et al. & 2011 & Northern Europe & $\mathrm{x}$ & \\
\hline 5 & 158 & 32 & Rawal et al. & 2015 & Southern Australia & $\mathrm{x}$ & $\mathrm{x}$ \\
\hline 5 & 540 & 108 & Diskin et al. & 2012 & Northern Europe & $\mathrm{x}$ & $\mathrm{x}$ \\
\hline 20 & 371 & 19 & Gallagher et al. & 2009 & Southern Australia & $\mathrm{x}$ & $\mathrm{x}$ \\
\hline 20 & 1108 & 55 & Davis et al. & 2015 & North America & $\mathrm{x}$ & $\mathrm{x}$ \\
\hline 28 & 1587 & 57 & Panchen et al. & 2012 & North America & $\mathrm{x}$ & $\mathrm{x}$ \\
\hline 36 & 460 & 13 & Hart et al. & 2014 & Eastern Himalayas & $\mathrm{x}$ & \\
\hline$>37$ & 372 & 10 & Primack et al. & 2004 & North America & $\mathrm{x}$ & $\mathrm{x}$ \\
\hline 39 & 216 & 6 & Lavoie \& Lachange & 2006 & North America & & $\mathrm{x}$ \\
\hline 39 & 5424 & 139 & Molnár et al. & 2012 & Northern Europe & & $\mathrm{x}$ \\
\hline 41 & 909 & 22 & Li et al. & 2013 & Eastern Himalayas & $\mathrm{x}$ & $\mathrm{x}$ \\
\hline 42 & 142 & 3 & $\begin{array}{l}\text { Miller-Rushing et al. } \\
\text { Primack \& }\end{array}$ & 2006 & North America & $\mathrm{x}$ & $\mathrm{x}$ \\
\hline 43 & N/A & N/A & Miller-Rushing & 2012 & North America & & $\mathrm{x}$ \\
\hline 87 & N/A & $\mathrm{N} / \mathrm{A}$ & Neil et al. & 2010 & North America & & $\mathrm{x}$ \\
\hline 141 & 5053 & 36 & Calinger et al. & 2013 & North America & $\mathrm{x}$ & \\
\hline 186 & 30,000 & 161 & Bertin & 2015 & North America & & $\Delta \bar{x}$ \\
\hline 370 & 1125 & 3 & Searcy & 2012 & North America & & $\Delta \bar{x}$ \\
\hline 1185 & 5949 & 5 & Park & 2012 & North America & & $\mathrm{x}$ \\
\hline$>1700$ & 19,328 & 11 & Park & 2014 & North America & $\mathrm{x}$ & \\
\hline 24,105 & 823,033 & 34 & Park \& Schwartz & 2015 & North America & $\mathrm{x}$ & $\mathrm{x}$ \\
\hline
\end{tabular}

